Techniques \& Culture

\title{
À la frontière du cru
}

Le congelé en Yakoutie (République de Sakha)

Isabelle Bianquis et Isabella Borissova

\section{OpenEdition}

Journals

Édition électronique

URL : https://journals.openedition.org/tc/8899

DOI : $10.4000 /$ tc. 8899

ISSN : 1952-420X

Éditeur

Éditions de l'EHESS

\section{Édition imprimée}

Date de publication : 17 mai 2018

Pagination : 108-111

ISBN : 978-2-7132-2750-9

ISSN : 0248-6016

Référence électronique

Isabelle Bianquis et Isabella Borissova, «À la frontière du cru », Techniques \& Culture [En ligne], 69 |

2018, mis en ligne le 17 mai 2020, consulté le 29 septembre 2022. URL : http://

journals.openedition.org/tc/8899; DOI : https://doi.org/10.4000/tc.8899 


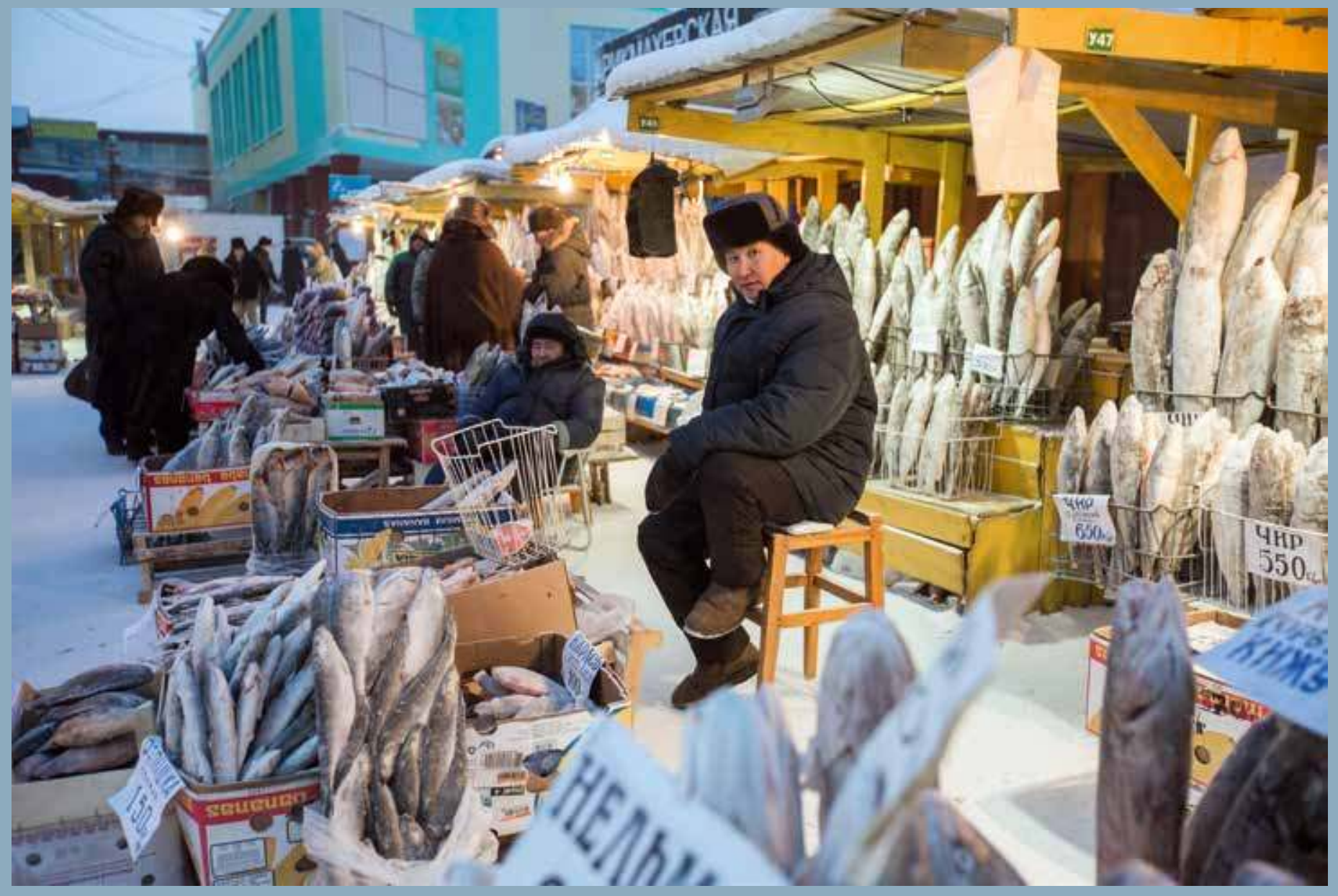




\section{À la frontière du cru Le congelé en Yakoutie (République de Sakha)}

Si la conservation par le froid naturel est connue depuis les temps préhistoriques, elle n'a pas pour seul but d'assurer le lendemain. Elle ne se résume pas à une technique destinée à transcender les saisons, à différer la consommation, à gérer un stock, à « prévoir la faim ». C'est pourquoi, en Yakoutie particulièrement, il faut distinguer ce qui est congelé à des fins de conservation et congelé pour satisfaire un goût (même si en réalité les deux options ne sont pas indépendantes l'une de l'autre).

D'où vient l'appétence des Yakoutes pour des aliments crus congelés, consommés très froids, en cours de décongélation, alors même que ce pays connaît durant la période hivernale les plus grands froids de la planète? La dégustation de ces produits représente en effet aux yeux des consommateurs une véritable délicatesse et le plaisir semble se nicher dans la perception d'un aliment décongelant doucement sous la langue et libérant ses saveurs. Ces aliments sont en nombre limité, il s'agit essentiellement de viande de poulain, de cheval, de renne, de certains poissons gras de la famille des salmonidae, de baies ou encore de quelques produits laitiers. Ce plaisir est-il lié à un goût pour le froid ou bien à un goût pour le cru que l'on pourrait ainsi consommer toute l'année grâce à cette technique de conservation?

À y regarder de plus près, l'opposition classiquement éprouvée entre le cuit et le cru, la nature et la culture doit être, dans le cas de la Yakoutie, augmentée d'un troisième terme celui du cru-congelé, profondément ambivalent, ni cuit ni cru... Le cru-congelé se présente comme une transformation du cru, un produit aux qualités gustatives et structurales modifiées. Il n'est pas complètement cru et cette propriété le place dans une zone intermédiaire, une zone frontière entre nature et culture. Le cru-congelé semble débarrassé de son côté sauvage tout en étant profondément lié à ce que la nature a de plus sauvage et en même temps de meilleur. Il garde toutes les propriétés bénéfiques de cette nature considérée comme vierge de contamination mais sans référer au goût du cru qui représenterait la partie négative du sauvage; il s'agit en quelque sorte d'un cru culturalisé. 
Ce plaisir gustatif se double d'une référence profondément identitaire. Comment comprendre la relation établie par les Yakoutes entre des pratiques de conservation et de consommation liées au cru, congelé et décongelé et l'affirmation d'une identité spécifique? Les Yakoutes aiment se définir comme les «enfants de la Nature et voient dans une alimentation saine la représentation d'un idéal de pureté lié à la nature. La triple valeur ajoutée de cette technique tient à sa fonction de conservation, au plaisir gustatif et à l'inscription dans un environnement naturel idéalisé, occupant le sommet de la hiérarchie des symboles. Alors que deviennent les «enfants de la Nature» dans un contexte urbain contemporain? Sous quelle forme cette référence à la nature se maintient-elle? Pourquoi garde-t-elle cette fonction profondément identitaire? L'étude des usages alimentaires dits «traditionnels» en milieu urbain, et plus spécifiquement dans la restauration (Bianquis \& Borissova 2015), permet de saisir les modalités de construction d'une gastronomie conjuguant des éléments empruntés à la tradition (en particulier ces produits

Restaurant Tygyn Darkhan. Chef débitant le poisson stroganina

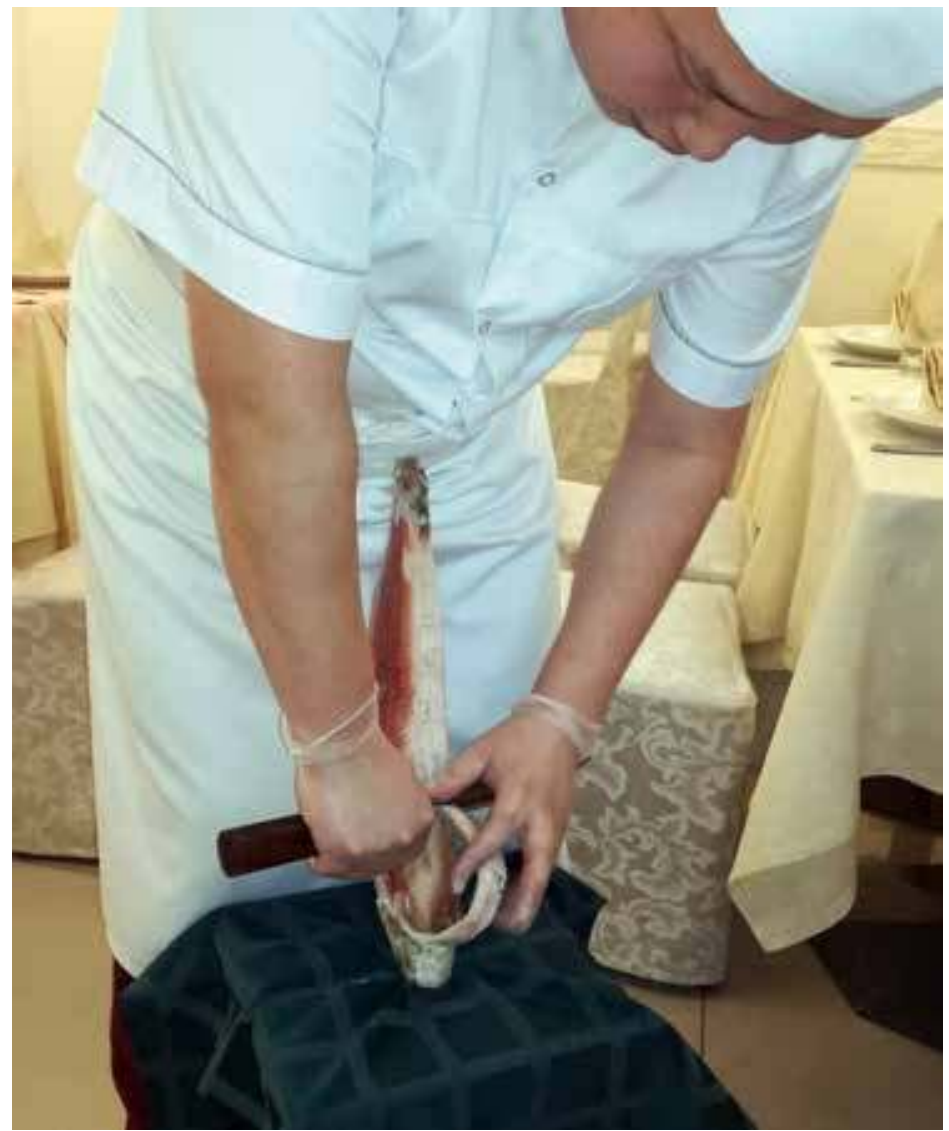

crus/congelés) et la modernité, entendue comme une source infinie d'inspiration. Ces métissages, ces juxtapositions d'ingrédients, de techniques, de recettes, de présentations dévoilent des combinaisons élaborées par des «chefs», nouvelles stars très médiatisées, empruntant à un répertoire culinaire ancré dans l'ordinaire, le quotidien, le monde rural et une cuisine qui se veut raffinée, contemporaine, voire expérimentale, inspirée, pour partie, par des modèles exogènes. Ces chefs, entrepreneurs et garants de la mémoire, mettent en avant l'importance d'un goût naturel, sans artifices, pourtant les usages viennent d'une certaine façon contredire ce discours. Les produits sont agrémentés de sel et d'épices et «recontextualisés dans une nouvelle offre gastronomique» (Matta 2010: 8). Peut-on alors parler de petite cuisine et de haute cuisine comme le suggérait Goody? (Goody 1984) La séparation n'est pas si nette, car le rôle des médias, les émissions culinaires et autres manifestations réintroduisent dans les foyers la valeur d'une cuisine rurale retravaillée certes, mais dotée de prestige. Il nous faut donc repenser la question de la hiérarchie en y inscrivant une double face. Par le recours à des produits ou des plats du monde 
rural, à la médiocre réputation, jugés frustes et sans saveur, la grande cuisine véhicule deux messages. Le premier à destination des élites locales marque une séparation entre des classes sociales (le paysan et le citadin) et instaure en quelque sorte un processus de «civilisation des mœurs». Le second message relève d'une construction identitaire. Profondément ancré dans une représentation idéalisée d'une nature «vierge», cet imaginaire instaure une séparation entre la culture yakoute et le reste du monde, il mobilise un processus qui transcende les classes sociales. La promotion de certains produits ou plats phares permet alors la mise en scène d'une cuisine que l'on peut qualifier de «trad-innovante» dans laquelle la conservation n'apparaît jamais comme une simple technique.

\section{En ligne}

Retrouver l'article complet sur journals.openedition.org/tc: Techniques\& Culture 69 «Le temps des aliments».

\section{Iconographie}

Image d'ouverture. Marché paysan, Yakutsk 2017. Le marché de la capitale dit «marché paysan» se compose de deux espaces. Le premier, situé en extérieur est occupé exclusivement par des étals de produits congelés (durant

la saison hivernale) locaux (viande, poisson, baies) et légumes ou fruits (importés). Ici présentation de diverses espèces de poissons. (C) Mitchil Stepanovitch Yakovlev.

1. (C) I. Bianquis.

\section{Ies auteures}

Isabelle Bianquis est professeur d'anthropologie à l'université François-Rabelais de Tours, membre de l'UMR Citeres. Ses recherches portent sur l'instrumentalisation de la tradition et les nouvelles pratiques alimentaires en Mongolie et en Sibérie.

Isabella Borissova est professeur de philologie à la North-Eastern Federal University de Yakutsk (République de Sakha Russie). Ses recherches portent sur les formes de l'ethnicité, la langue, la culture et les sociétés en Sibérie.

\section{Références}

Bianquis, I. \& I. Borissova 2015 «Urban melting-pot: Food heritage in Yakutia» in C. Man Kong Lum \& M. de Ferrière le Vayer dir. Urban Foodways and Communication: Ethnographic Studies in Intangible

Matta, R. 2010 «"L'indien" à table dans les grands restaurants de Lima (Pérou)», Anthropology of food 7. [En ligne] : aof.revues.org/6592. Cultural Food Heritages Around the World. New York: Rowman \& Littlefield Publishers, INC. : 169-185.

Goody, J. 1984 [1982]. Cuisines, cuisine et classes. Paris: Centre Pompidou.

\section{Pour citer l'article}

Bianquis, I. \& I. Borissova 2018 «À la frontière du cru. Le congelé en Yakoutie (République de Sakha)», Techniques ECulture 69 «Le temps des aliments», p. 108-111. 